\title{
La revolución húngara de 1956 según la diplomacia española
}

\author{
Maria Dolores Ferrero Blanco *
}

\begin{abstract}
RESUMEN
ABSTRACT

Este articulo trata de la percepción

This article deals with the perception of Spanish authorities about the que tuvieron las autoridades españolas Hungarian Revolution of 1956, through sobre la revolución húngara de 1956. según las versiones de los diplomáticos españoles, especialmente al embajador de España en Bonn, Antonio María Aguirre; el embajador de España en Viena, José de Erice y el delegado de España en la ONU, José Félix de Lequerica. Cada informante aporta aspectos diferentes que ofrecen nuevas perspectivas sobre cuestiones referidas a la disidencia húngara y sobre los intereses de España derivados de su acendrado anticomunismo.

PALABRAS CLAVE Revolución húngara, diplomáticos, embajadores, Naciones Unidas, anticomunismo. the versions of its diplomats abroad. The information provided by the ambassador of Spain in Bonn, Antonio Maria Aguirre; the ambassador of Spain in Vienna, José María de Erice and the delegate of Spain in the UN, José Félix de Lequerica, is studied with particular attention. The information of the three is complementary and provides unknown perspectives about the hungarian dissidence in some aspects and about the interest aroused in Spain because of its pure anticomunism.

KEY WORDS

Hungarian Revolution, diplomats, ambassador, United Nations, anticomunism.
\end{abstract}


Desde la muerte de Stalin, las voces húngaras disidentes habian solicitado de forma continuada la libertad para elegir su propia «vía al socialismo", según habían entendido tras el xx Congreso del PCUS, y la retirada de las tropas soviéticas apostadas en Hungría desde el final de la Segunda Guerra Mundial. En este ambiente de efervescencia y esperanza que había propiciado Jrushchov, se unieron todos los descontentos en una manifestación multitudinaria el 23 de octubre de 1956, planteada inicialmente como un apoyo a las reivindicaciones polacas - que habían comenzado por protestas obreras en Poznan-, pero a las que enseguida se aunaron las demandas propias de Hungría: un cambio político en que Imre Nagy - que representaba el sector reformador dentro del partido comunista húngaro - tomara el poder como Presidente. La manifestación comenzó siendo de estudiantes, pero desde su inicio se le fueron uniendo obreros, empleados, intelectuales, algunos políticos "revisionistas» y ciudadanos de Budapest de todos los ámbitos hasta contar en unas horas con unas 400.000 personas, en una ciudad de 1.000 .000 de habitantes. Cuando la manifestación llegó al pie de la estatua de Sendor Petöfi y alcanzó el Parlamento, fue disuelta violentamente por la policía secreta $(A V H)$, del estalinista Gerö contra el que se luchaba, provocando unos 100 muertos y más de 200 heridos. Más tarde, el ejército se puso de parte de los insurgentes con Pal Maleter al frente $y$, ante los hechos que amenazaban un caos imprevisible, desde Moscú se aceptó que Imre Nagy fuera nombrado Presidente. Sólo lo pudo ser, sin embargo, desde el 25 de octubre hasta el 4 de noviembre, en que se produjo la gran invasión de las tropas soviéticas.

Imre Nagy, aceptando un liderazgo que realmente le fue impuesto, planteó una reforma a fondo del socialismo húngaro en la que se incluyó, entre otras muchas, una medida tan radical como lo era el que el Partido Comunista dejara de ser el partido dirigente de la sociedad y. por tanto, se abrieran las puertas al pluripartidismo. Moscú, aunque en teoría había ido aceptando las reformas de las que Nagy había dado parte puntualmente, temió que Hungría fuera el comienzo de la desintegración del bioque comunista y en unos días respondió con la irivasión de sus tanques. Cuando Nagy se percató de la irtención usá se sintió trácionácio y quecó iniciaimente tan asombrado que plarteó :a me zide més radical: !z szlicz de Hungría del Pacto de Varsovia, lo yve romja otis de las "Eg:e.s sagradas de la URSS. Asimismo, en una ingenua fe en Occidente, que habia repetido incarisablemente desde los Acuerdos de Yalta que su cometido era el de valedor de las libertades, Imre Nagy pidió ayuda a la ONU y confió, durante casi todo el tiempo de lucha y barricadas en las calles, en que las Naciones Unidas llegarian en ayuda del pueblo húngaro. Pero nada de eso ocu- 
rrió. Occidente no reaccionó, la ONU deliberó planteándose la cuestión durante siete años, pero no llegó a actuar de ningún modo contundente y en Hungría, además de unos 200.000 huidos, y un número muy discutido de muertos -entre 10.000 y 20.000 - la represión posterior continuó hasta 1963. Además, en 1958 fueron juzgados sumariamente y ejecutados Imre Nagy y sus más próximos colaboradores '.

\section{LA VERSIÓN DE LA DIPLOMACIA ESPAÑOLA}

En líneas generales, la versión que los diplomáticos españoles transmitieron de los hechos de Hungría a las autoridades políticas españolas, no difirieron esencialmente de las ofrecidas en otros países. Se conoció la situación en todo su detalle y complejidad, amén de que ciertas interpretaciones y comentarios de los diplomáticos estuvieran frecuentemente aderezadas de sus propias concepciones, preferencias ideológicas y otras influencias.

Las relaciones oficiales de Hungría con España se habían suspendido el 25 de abril de 1945, pero sus diplomáticos se quedaron en España y gozaron de un trato excelente por parte de las autoridades españolas, por lo que Francisco de Marossy quedó como representante oficioso de la Monarquía Húngara y siguió al frente de la Legación Real de Hungría desde el 4 de marzo de 1949 hasta el 20 de octubre de 1969. Marossy había sido diplomático en varias ciudades europeas y se encontraba en Helsinki cuando Finlandia y la URSS firmaron la paz en 1944 y los representantes de los antiguos aliados del Eje debieron abandonar el país. Marossy se decidió por España porque ya había estado en la década de 1930 como Encargado de Negocios, por lo que llegó a España el 15 de abril de $1946^{2}$. Le ayudó también en sus pretensiones representativas en España que el recién creado Comité Nacional Húngaro de Nueva York le había nombrado su representante en nuestro país. Él, sin embargo, aspiraba a más y lo que deseaba de verdad era seguir en la antigua legación de Paseo de la Castellana, n. ${ }^{\circ} 49$. Era un objetivo casi imposible, pero en

Acerca del tema de la Revolución Húngara de 1956, está casi ultimado un libro en el que se tratará todo el proceso, la represión, la repercusión en el mundo, la actuación de la ONU y la versión de los hechos en España y que titularemos El primer intento democrático de Europa del Este. Represión comunista e indiferencia de Occidente.

2 Eiroa Sanfrancisco, M.: Las relaciones de Franco con Europa Centro-Oriental, Ed. Ariel, Barcelona, 2000. El libro en su totalidad ofrece una excelente y novedosisima información, detallada y precisa, acerca de las relaciones del Primer Franquismo, no sólo con Hungria sino con todos los países de Europa Centro-Oriental. 
enero de 1949 llegó a España Otto de Habsburgo y lo primero que hizo fue comunicarse con Marossy - muy partidario de los Habsburgo-- para que le orientara respecto a qué debía solicitar al Jefe del Estado español para poder ayudar a los húngaros. Él lo concretó en tres peticiones: entrega del edificio de la Legación, una emisora de radio para transmitir en húngaro y acogida de refugiados. Franco aceptó y el 4 de marzo de 1949 Marossy recibió los papeles y la sede de la Castellana ${ }^{3}$.

Desde ese momento la figura de Marossy fue de una excepcional importancia como intermediario entre las autoridades españolas y los húngaros que se afincaban en España, como garante de las peticiones de ayuda que se hacían al régimen español y, en concreto, como informador permanente de los políticos españoles - del ministro de Asuntos Exteriores sobre todo- de las noticias que le llegaban de Hungría. Fue también el cauce de los exiliados anteriores a 1956 -en realidad monárquicos que huyeron al implantarse el comunismo-, y quien en muchas ocasiones facilitó documentos $u$ opiniones del Archiduque Otto de Habsburgo o respaldó contactos con personas que con frecuencia poseían títulos nobiliarios ${ }^{4}$. En alguna otra ocasión también propició encuentros individuales o de grupo, con exiliados procedentes de la década de 1930, cuando crecieron los adeptos a movimientos totalitarios, sobre todo por desavenencias con los Aliados por el resultado territorial del Tratado de Trianon, que tan perjudicial había sido para Hungría. En cualquier caso, es algo resenable que los grupos o individualidades que el Gobierno español consideró adecuados para informarse de la situación húngara y entraron en contacto con el Ministerio de Asuntos Exteriores —además de los avalados por sus diplomáticos - no fueron ciudadanos o intelectuales exiliados seguidores de Imre Nagy, o miembros de su Gobierno en el exilio, por ejemplo, sino, sobre todo, los recomendados por Marossy.

Marossy fue, por otra parte, una de las personas más interesadas en que en la ONU se tratara el tema de Hungría, para lo que solicita constantemente la mediación española que era muy valorada en el sector más

3 Entrevista a Zoltan Ronay, húngaro exiliado en España desde 1945. Fue culaborador en diversas publicaciones --especialmente en Oriente Europeo, rev sta irimestral del Cinti o dé Estudios Oriantles- y en las actividades que se llevaban en España por la causa húngara desde su llegada a España. Entrevista realizada en Madrid en marzo de 1999.

4 Uno de los casos fue el del representante de los "patriotas húngaros en el exterior» en $\mathrm{Mu}$ nich, el Conde de Pongartz, que Marossy recomienda al Ministerio de Exteriores, a la vez que rechaza a un "supuesto" Jefe del Consejo Húngaro en Alemania, Imre Pataky, del que Marossy dice haber averiguado que es una persona desacreditada entre sus compatriotas por traficar irregularmente con divisas. Carta del Cónsul de España en Munich, R. F. Quintanilla, del 20 de octubre de 1956. Archivo del Ministerio de Asuntos exteriores, (en adelante AMAEX), R-4466-2. 
poderoso de la ONU por ser España un país de reconocido anticomunismo en una época tan marcada por el enfrentamiento entre los bloques. Además de este cauce, el resto de las informaciones que llegaban al Gobierno español respecto a Hungría se produjeron fundamentalmente por dos vías: una, desde la ONU, a través de Diego Buigas de Dalmau, Jaime de Piniés y, sobre todo, José de Lequerica, a lo largo de todo el periodo en que el tema húngaro se debatió en la Asamblea General (en los periodos $X \mid$ a XVII); la otra, desde pocos días después del levantamiento, por las explicaciones que trasladaban a España con toda urgencia, tanto la Embajada española en Bonn, a través del embajador José María Aguirre, como la Embajada española en Viena, a través de su homólogo, José de Erice.

Sólo tres días después del levantamiento, el 26 de octubre de 1956, el Marqués de Santa Cruz, Subsecretario de Asuntos Exteriores español, recibió un mensaje de Marossy, en nombre del Archiduque Otto de Habsburgo. Marossy le comunicaba en él que el Archiduque le rogaba que tomara la iniciativa de dirigirse al Consejo de Seguridad de la ONU para protestar por la intervención soviética en Hungría "confiando en la caballerosidad del Jefe de Estado Español, siempre "primer campeón" en Europa de la causa de los pueblos oprimidos" 5 . Esta solicitud de mediación fue sólo la primera de una larga serie de peticiones que se harían al Gobierno español, desde diferentes instancias de los sublevados húngaros, lo que dio un carácter singular a la participación española en estos hechos y al interés que mostraron sus representantes en distintos ámbitos de la vida política.

Cursada la petición desde España y entre los días 27 y 28 de octubre, el Delegado de España en la ONU, Diego Buigas de Dalmau, envió al Ministerio de Asuntos Exteriores cuatro telegramas dando cuenta de las gestiones llevadas a cabo por él a este respecto. Buigas informaba al ministro de que habia sido recibido por el Secretario General de la ONU al que había entregado una nota, en nombre del Gobierno de España, protestando por la «sangrienta intervención de las tropas soviéticas en conflictos internos de Polonia y Hungría" y solicitando la intervención de las Naciones Unidas. También le comunicaba que habia más países que se proponían dar el mismo paso que España de interceder por Hungría y que había

5 Este tipo de calificativos son frecuentes al Jefe de Estado español, al que valoran sobre todo por ser de los más interesados en esgrimir una bandera contra el comunismo y olvidan absolutamente que se trate de un régimen dictatorial que ejerce internamente una fuerte represión. Lo único que importa a los diplomáticos húngaros que acceden a los representantes españoles de cualquier indole es que sean contrarios a la URSS. Carta de Marossy del 26 de octubre de 1956. AMAEX, R-4294-6. 
que examinar despacio la base novena de la Carta de Naciones Unidas para estudiar el procedimiento por el que se debía intervenir ${ }^{6}$.

El Secretario General de la ONU le habia agradecido a Buigas especialmente la redacción de la nota española por no mencionar ni insinuar siquiera ningún procedimiento concreto a seguir. Lo consideraba un tema muy delicado, que debía pensarse muy bien y ponía en su conocimiento que con ese fin ya se encontraban reunidos los representantes permanentes de EEUU y Gran Bretaña con el Presidente del Consejo de Seguridad de la ONU ${ }^{7}$. Ese mismo día, en efecto, los representantes permanentes de EEUU y Gran Bretaña solicitaron una reunión urgente del Consejo de Seguridad, en base al artículo 34 de la Carta de Naciones Unidas, a fin de examinar la situación creada en Hungría por las fuerzas militares extranjeras y la violenta represión que había tenido lugar, considerando que los derechos del pueblo húngaro tenían que estar garantizados por el Tratado de Paz del que todos habían sido firmantes ${ }^{8}$.

El día 28 de octubre se reunió por fin el Consejo de Seguridad para tratar de qué estaba ocurriendo en Hungría, con la oposición del representante de la URSS que sólo admitió calificar la situación de "problemas internos» y el ataque de los tanques como «la entrada en Budapest de algunos refuerzos que había solicitado el gobierno húngaro". En resumen, en esa sesión y otra que se celebró al día siguiente, se aclaró que, en efecto, habian entrado tropas rusas en Hungría. Sin embargo, cuando el día 29 empezó la entrada de las tropas israelíes en el Canal de Suez, cambió el objetivo de todos y no se retomarian los debates sobre Hungría hasta dos dias después, el 1 de noviembre, ya en la Asamblea General ${ }^{9}$.

Los embajadores José María Aguirre y José de Erice aportan dos tipos de información que tienen un interés de primer orden para la visión española de los hechos, por el carácter complementario de una y otra. José María Aguirre es un cronista de los hechos, que ante todo trata de describir cronológicamente lo ocurrido y redacta informes muy detallados del transcurso de los días y de otras cuestiones esenciales, mientras que los aspectos elegidos por José de Erice en sus comunicados son fundamentalmente

6 Telegrama n. 86 del Delegado de la ONU. Archivo del Ministerio de la Présidencia del Gobierno. Jefatura del Estado, Leg. 1686, 1.1.

7 Telegrama n. 87 del Delegado de la ONU. Archivo del Ministerio de la Presidencia del Gobierno. Jefatura del Estado, Leg. 1686, 1.1.

8 Telegrama n. 89 del Delegado de la ONU. Archivo del Ministerio de la Presidencia del Go bierno. Jefatura del Estado, Leg. 1686, 1.1.

9 Telegrama n. 90 del Delegado de la ONU. Archivo del Ministerio de la Presidencia del Gobierno. Jefatura del Estado, Leg. 1686, 1.1. 
de opinión, del análisis que él hace del comportamiento de Occidente, que encuentra lamentable, y de las actitudes de todos los posibles participantes en el tema: la URSS, Europa, Tito y la ONU. Comenzaremos, por tanto, por José María de Aguirre, ya que la manera pormenorizada en que expone los hechos sirve de recordatorio de los mismos, antes de entrar en el tratamiento de otras cuestiones. A estos dos canales de información, desde las proximidades de Hungría, se unieron las aportaciones del Embajador español en la ONU, José Félix de Lequerica, que expondremos en tercer lugar.

\section{EL INFORME DEL EMBAJADOR DE ESPAÑA EN BONN, JOSE MARIA DE AGUIRRE}

Los temas tratados por Aguirre en diferentes cartas y comunicados, podrían sintetizarse en los siguientes: una reconstrucción de la cronología de los hechos de los meses de noviembre y diciembre de 1956; las causas y carácter de la insurrección; la composición de las tropas, tanto de las apostadas en Hungría como de las que invadieron; las motivaciones de la URSS para invadir cuando lo hizo y, por último, los tipos de ayudas demandadas al Gobierno Español.

\subsection{La cronología de los hechos fundamentales}

Desde el 23 de octubre al 1 de noviembre el triunfo de Nagy y sus seguidores parecía seguro, sin embargo, el día 1 de noviembre sobrevino la decepción cuando se supo que las tropas rusas se habian retirado de Budapest, pero no de otras regiones. Incluso se comprobó que habian sido reforzadas con otras recién llegadas para cerrar herméticamente la frontera austríaca y ocupar los principales centros ferroviarios del pais.

Entre los días 2 y 8 se iría fraguando la victoria de los soviéticos. Nagy había emitido una protesta formal a Rusia y le había solicitado enérgicamente la total retirada de las tropas soviéticas y el comienzo de negociaciones en pie de igualdad, pero, pese a ello, el mismo día 2 por la noche Nagy denunciaba a la ONU la presencia de nuevas tropas que marchaban en dirección a Budapest y pedía al Secretario General de la ONU que invitase a las grandes potencias a reconocer su neutralidad, cosa que la ONU no hizo. En la noche del 3 al 4 todavía la mayor parte de los miembros del Gobierno Nagy fueron engañados por las declaraciones del Embajador soviético que había prometido no actuar contra ellos y después lo 
hizo. El Jefe del Estado Mayor y el Ministro de Defensa habían ido a negociar, sin contemplar siquiera la posibilidad de que les pudieran detener sus interlocutores, pero fueron detenidos. Esa misma noche, tanques y blindados rusos se aproximaron a la capital y a las cuatro de la mañana comenzó el ataque combinado de artillería y aviación que siguió al día siguiente, en que atacaron 15 de las 19 divisiones y prácticamente lograron aplastar el movimiento. El éxito tan rápido de la invasión fue debido, según el Embajador, a la forma en que la URSS había organizado desde siempre los ejércitos de los países del área comunista: les había dotado de armas muy diversas, pero no de armamento anti-tanques de combate. El resultado fue que cuando los soviéticos llegaron con carros de combate, entre 2.500 y 3.500 , no encontraron ante ellos armas que pudieran frenarles.

El nuevo gobierno se había terminado de constituir el día 4 con Janos Kádár como Primer Ministro, Muernnich, como Ministro de Defensa y Horvath, de Negocios Extranjeros. Paralelamente, las radios de Budapest y de otras ciudades pedían angustiosamente auxilio a las grandes potencias occidentales y a la ONU. El Informe dice, tristemente que "los ciudadanos de los paises del Este, aislados del mundo, esperaban maravillas de la llegada de Hammaskjoeld, Secretario de las Naciones Unidas, pues no habían podido aprender, como otros, el valor tan relativo del Organismo de Nueva York». De cualquier modo, Radio Budapest, ya en manos del Gobierno Kádár, anunció que el nuevo gabinete se oponía a que la cuestión húngara fuese llevada a la ONU.

Por fin, el día 5 los insurrectos empezaban a admitir su derrota. Fue una jornada muy intensa y reinaba la confusión: se desconocia la suerte de Nagy, aunquie se supo algo más tarde que otros dos personajes emblemáticos, como el Cardenal Mindszenty y Anna Ketly estaban a salvo. Anna Ketly, presidente del Partido Socialdemócrata húngaro y Ministro del Gobierno de Nagy, había logrado salir del país por Viena y se dirigía a Nueva York para defender en las Naciones Unidas la causa del pueblo húngaro y el Cardenal habia encontrado asilo en la Embajada americana de Budapest. En este sentido, una información dada por un periodista el día de la solicitud de asilo del Cardenal Mindszenty muestra la consideración que tuvo con él el Gobierno de Imre Nagy, que llamó al prelado cuando entraron las tropas en la madrugada del 4 de noviembre. Dice así:

«Al Cardenal le despertaron los cañonazos, como a todo el mundo en Budapest. Minutos después le llamaron poir teléfono y le comunicaron que Nagy y su Gabinete estaban reunidos en el Parlamento y le pedían que acudiera allí. El Cardenal y su secretario, Turchanyi, se pusieron en marcha, pero les detuvieron los rusos. Cuando les iriterrogaron, ante la respuesta de que les había convocado el gobierno, los rusos les dijeron que no tenía sen- 
tido que les hubiera llamado "un gobierno húngaro" porque ellos eran ahora ios que tenían controlada la situación. Pese a todo, aprovechando un descuido, Turchanyi logró alcanzar el coche y con disparos a su espalda, se dirigió a la Embajada americana a pedir asilo político" ${ }^{10}$.

Ya por la mañana, Kádár dio un comunicado en el que explicaba que él se había separado el 1 de noviembre del Gobierno de Nagy porque éste "Se hacía de día en día más contrarrevolucionario". También aseguraba Kádár que deseaba para el futuro "un gobierno de carácter nacional», a la par que prometía "crear consejos obreros y entablar relaciones con Moscú para la retirada de las tropas soviéticas y para terminar con la colectivización en el campo". Asimismo pedía ayuda al pueblo para lograr la "exterminación del fascismo en Hungría" e informaba de que había escrito a Hammaskjoeld, exponiéndole que el tema era "interno de Hungría" y no procedía que fuera llevado a la ONU. Con todas estas medidas, en la noche del día 5 el movimiento prácticamente había sido sofocado y el Gobierno Kádár difundía por todas partes que las autoridades soviéticas habían prometido amnistía a las personas que depusieran las armas antes del día 6 .

Esta era una repetición de las garantías que ya había ofrecido en su discurso por radio del día 4 de noviembre cuando prometió personalmente inmunidad a todos los participantes en el levantamiento, siempre que dejaran las armas. La población había hecho entonces caso omiso de ese ofrecimiento y, de hecho, se comprobó después que si le hubieran creído, no hubiera servido de nada. El 22 de marzo siguiente, ya en 1957, la sección penal del Tribunal Supremo de Budapest se manifestaría respecto a aquella "promesa» y daría su interpretación técrica acerca de la declaración de Kádár: según A. Dorbach, se supo entonces que el Tribunal concluyó que esa promesa no habia tenido nunca respaldo legal ya que la amnistía sólo la podía decretar el Gobierno y no Kádár de forma individual ${ }^{11}$.

Por lo que se refiere a la localización geográfica de la resistencia, Aguirre destaca la diferencia entre la capital, Budapest, y las provincias y expone con bastante detalle la situación de los insurgentes. Señala que en los primeros días del levantamiento, las fuerzas de resistencia estaban completamente dispersas por el avance de los tanques rusos y por el «paraguas" que a éstos les proporcionaba la aviación, que controlaba todo el espacio aéreo con unos 1.500 aparatos. Todo el país había sido ocupado y tanto las mayores ciudades como los pueblos de cierta importancia estaban siendo patrullados por las fuerzas soviéticas. Esa noche se calculó

10 BaIN B. L.: “Mindszenty's escape», en Daily Express, London, 7-12-1956

11 Dornbach, A.: The Secret Trial of Imre Nagy. Praeger Publishers, 88 Post Road West, Westport, CT06881. United States of América, 1994, pág. 5. 
que había en Hungría 17 divisiones llegadas desde Rusia por Ucrania, la mayoría por avión, que era la forma más fácil porque Hungría contaba con un buen aprovisionamiento de campos de aviación.

En Budapest, incluso en la noche del 5 al 6 , cuando ya muchos lo daban todo por perdido, en el distrito octavo, continuaba una resistencia feroz y aun creían que la lucha podia durar algunos días más. Sin embargo, era imposible prestarles ayuda, tanto por la confusión que reinaba en la ciudad, como por que se trataba de islotes aislados que no se sabía donde estaban hasta que se encontraban. Pero, como ya indicamos, una cosa era Budapest y otra bien distinta el resto de Hungria: mientras Radio Budapest, ya en manos de los soviéticos, no cesaba de incitar a la vuelta al trabajo y de anunciar la reanudación del servicio ferroviario, continuaba la lucha en el Este y en el Sur del país. En el Este, se había tenido noticia de éxitos puntuales de los sublevados por una emisora interceptada y se supo que seguían luchando en las regiones de Dunafoldvar, Dunapentele y Sajoszentpéter, pero se esperaba que la victoria rusa sería un hecho al día siguiente a lo sumo. Radio Pecs, al sur del pais, también denunciaba, todavía el día 5, focos de resistencia en las minas de uranio de la región, en donde se supo que existía un enclave resistente de $20 \mathrm{Km}$. cuadrados, pero que ya escaseaban las armas y la munición, y se esperaba una pronta retirada. También en el Sur, la ciudad de Szeged, en Yugoslavia, se estaba convirtiendo en paso de dirigentes revolucionarios húngaros huyendo de la represión. Por último, el lugar que los más optimistas habían esperado que fuera "el punto de respuesta" al ataque soviético, que estaba preparado para recibir una posible ayuda militar de Occidente, la ciudad de Szombathely, había caido también el día 5, al parecer, por una información que había llegado a las fuerzas rusas desde sus servicios secretos que se habían ido organizando en el Burgenland austríaco, con cientos de agentes, sin que las autoridades húngaras pudieran detenerles.

El ultimátum que había sido anınciado por Radio Pecs, para la entrega de las armas sin represalias, terminaba a las 9 de la mañana del dia 6 , sin embargo aún continuaban los combates en ciertos lugares de Budapest y de otros puntos del país. Aguirre se muestra alarmado por el hecho de que el autodenominado Gobierno Kádár-Munnich-Lossonszy no tenía apoyo ninguno entre la población: ni policía -la mayoría de los AVH habían perecido en los combates callejeros-, ni administración, ni ciudadanía y sólo se podía apoyar en el ejército soviético. Daba cuenta de que los Juzgados en ese momento sólo estaban integrados por rusos, lo que hacía suponer que las sentencias por actos de rebelión tendrían que ser dictadas por tribunales soviéticos. Calificó la situación política de extraordinaria e informaba de que había comenzado la represión en la capital, se 
habían producido fusilamientos y todos esperaban una masacre de grandes proporciones y una deportación masiva de prisioneros hacia la URSS, como había sucedido en la ciudad de Nyiregyhaza, donde los soviéticos habían conducido a su población hacia la Ucrania Carpática. Se decía irónicamente que «Hungría podría proveer a la URSS de nueva sabia para sus campos de trabajo forzados" y consideraba inimaginable en esos momentos que en adelante se pudiera establecer un régimen estable en Hungría, ni siquiera comunista ${ }^{12}$.

La guerra se estaba convirtiendo en una "guerra de guerrillas" excepto algunos núcleos resistentes de Budapest. El día 7 aún seguían los combates en Pecs y Moscecz, pero ya se distribuía un manifiesto de Kádár ordenando la vuelta al trabajo. En Moscú habían comenzado las celebraciones por el aniversario de la revolución de octubre y en un discurso, Souslov se atrevió a decir que la línea de política exterior del gobierno ruso despertaba simpatías en todo el mundo y se jactó de haber aplastado la revolución húngara. Sin embargo, el embajador Aguirre informaba de que no asistieron apenas diplomáticos extranjeros a la fiesta y que sólo habian ido dos de Alemania Federal y ninguno de ellos era del Bundestag, ni del Bundesrat, ni politicos ni periodistas.

El día 8, Radio Budapest, ya controlada por el Gobierno Kádár, seguía insistiendo en la vuelta al trabajo por falta de provisión alimentaria, pero señalaba que todavía se combatia en los hoteles Royal y Continental de Budapest, seguian las guerrillas en el resto del país y habia una resistencia encarnizada Dunapentale. El nuevo Gobierno Kádár prestaba juramento ante el Presidente del Presidium húngaro, mientras cientos de miles de trabajadores seguian en huelga, sobre todo en transportes, industrias alimentarias y minas, en medio de disturbios y algunas voladuras con dinamita de las minas de uranio de Pecs. Incluso el día 10 se habló de que algunos miembros del anterior Gobierno de Nagy querían colaborar con Kádár.

Entre los dias 11 y 13, las informaciones se referian tanto a que la situación estaba controlada por los prosoviéticos, como a la tenaz persistencia de la huelga general. Kádár no confiaba en el cese del levantamiento y se dijo en algunos medios que había tenido lugar una entrevista entre él y Kádár que había trascendido y que Kádár había hecho algunas concesiones: supresión de la enseñanza obligatoria del ruso, sustitución de los uniformes soviéticos por los antiguos uniformes húngaros, aceptación de que se celebrara el día 15 de marzo la fiesta nacional de Hungría

12 Carta del Embajador de España en Bonn, Antonio M. ${ }^{a}$ Aguirre, del 7 de noviembre de 1956. AMAEX, R-4465-89. 
en recuerdo del levantamiento de 1848 y la destitución de la policía secreta. Pero ese mismo día pronunció un discurso en el que no hizo alusión alguna ni a la neutralidad de Hungría ni a la posibilidad de elecciones libres, que había sido la constante recomendación de la ONU en sus resoluciones. También ese día circularon rumores de que el Ministro de Defensa de Nagy, Pal Maleter, había sido detenido por los rusos cuando trataba de negociar la retirada de las tropas soviéticas, pero que había podido escapar y se había incorporado a una guerrilla de partisanos.

Lo cierto era que el Gobierno Kádár no terminaba de hacerse con la situación. Seguía la desobediencia civil de la población, la huelga se prolongaba e iban incrementándose las dificultades para el abastecimiento hasta el extremo que el día 13, ante las casi imposibles condiciones de supervivencia, Jruhchov fue a Hungria para estudiar la situación con Kádár. En Moscú se había empezado a dudar de la viabilidad del gobierno por la resistencia pasiva de la población y la persistencia de la huelga, pese a todas las dificultades. El ejército continuaba en Budapest y en la frontera checa y un gran grupo de intelectuales -técnicos y periodistas de la radio húngara, la Asociación de Escritores, la Federación de Estudiantes, la Federación de Artistas y la Asociación de periodistas- se reunieron en el Ministerio de Instrucción Pública y decidieron no volver al trabajo si el Gobierno no aceptaba tres condiciones: la retirada de las tropas rusas y su sustitución por la policía del país, elecciones libres y libertad de prensa para poder dar publicidad a todo lo ocurrido.

La resistencia del movimiento obrero era enorme y, según Aguirre, las noticias que llegaban a Bonn apuntaban a que sólo Nagy podría salvar la situación. Esa información pareció confirmarse cuando se supo que una delegación obrera había solicitado a Kádár que dejara su puesto a favor de Nagy y, una vez más, que se retiraran las tropas soviéticas. Él contestó que sólo se podrían retirar cuando se normalizara la situación. Entretanto el gobierno soviético envió 20 nuevas divisiones - no se sabía si para reforzar o para sustituir- de las que ya habian entrado en Hungría los primeros destacamentos el día 20 de noviembre. Como el Gobierno no cedía, la huelga continuaba tanto en Budapest como en los territorios occidentales y la situación de penuria alimenticia era cada vez mayor. Llegó a ser tan grande que la Federación de Sindicatus pidió a los obreros "la vuelta al trabajo sin que ello signifique abandonar los objetivos fundamentales del levantamiento nacional» y el embajador Aguirre llegó a escribir textualmente: «Esta semana será decisiva para el porvenir del Gobierno Kádár, ya que dependerá de que la masa de obreros húngaros acepte volver al trabajo. Todo indica que volverán, dada la situación angustiosa del país, pese a la gran descon- 
fianza en el gobierno" ${ }^{13}$. Sin embargo, al día siguiente, el día 21 , el Consejo Obrero de Budapest volvió a convocar una huelga de 48 horas de todas las industrias, salvo las alimentarias, reclamando otra vez la retirada de las tropas, la vuelta al poder de Nagy y el retorno de los deportados. Días después se supo que Nagy y sus colaboradores se habian refugiado en la Embajada yugoslava, la habian abandonado después y se desconocía su paradero. El Gobierno Kádár, para tranquilizar a la población, dijo que los refugiados habían solicitado trasladarse a Rumania, pero ese hecho no fue creído y motivó la protesta de Yugoslavia ${ }^{14}$. Entonces aún se desconocía que desde Rumania serían secuestrados por los rusos y terminarían siendo ejecutados.

\subsection{Las causas y el carácter del levantamiento húngaro}

Las causas a las que atribuyó el Embajador Aguirre el levantamiento coinciden con las señaladas por la mayoría de las fuentes y él las resume como los «abusos de diverso tipo del régimen que se venían cometiendo en Hungría desde la instauración del régimen comunista y que condujeron finalmente a la desesperación popular y a graves desórdenes». Señala, sin embargo, que la URSS y sus adeptos en Hungría, estaban intentando por todos los medios culpar a Austria de lo ocurrido: se decía que la causa de la insurrección había sido que Austria había violado su neutralidad y "había azuzado a 10.000 oficiales fascistas a protagonizar un levantamiento antipopular", además de estar concentrando tropas fascistas en la frontera, extremo que fue retransmitido incluso por Radio Moscú. Tanta fue la irisistencia en ese protagonismo de Austria que el Gobierno Austríaco llegó a temer que la URSS pudiera atacar con ese pretexto, al amparo del Tratado Internacional de Soberanía. En ese contexto, aún en el caso de que ese temor no se confirmara, Hungría no podía esperar ninguna ayuda eficaz de Austria.

Además de las causas del malestar húngaro, también hace Aguirre una breve alusión a los sectores de oposición que habian surgido en Hungría contra el régimen estalinista, y es curioso que destaca como organización clandestina más importante, la MEH, que agrupaba sobre todo a estudiantes universitarios católicos y no menciona entre los movimientos más

13 Informes de los dias 7, 14 y 20 de noviembre de 1956 del Embajador de España en Bonn, Antonio M. aguirre. AMAEX, R-4465-89.

Informes de los dias 21 al 27 de noviembre de 1956 del Embajador de España en Bonn, Antonio M. Aguirre. AMAEX, R-4465-89. 
importantes al Círculo Petöfi, que era el grupo literario-intelectual que todas las fuentes apuntan como el sector más crítico con el régimen y de donde procedía el propio Nagy.

También entre los envíos a España del Embajador existen dos Despachos - uno en español y otro en francés, sin firmas- que contienen una información singular y no mencionada en otras fuentes, acerca de un precedente muy importante del levantamiento húngaro: la celebración de una reunión secreta del Politburó, en Moscú, en septiembre de 1956, en la que los Servicios de Información Soviéticos, después de analizar la situación de protestas en Hungría, habian llegado a la conclusión de que podría haber desórdenes extremadamente importantes en un futuro próximo y, ante ello, el sector más duro del Politburó llegó a sugerir la conveniencia de hacer la guerra a Europa Occidental. Argumentaban para convencer al resto que EEUU no utilizaría sus super-armas y que bastaría con presentarlo como un «avance hacia el Atlántico».

Según el texto, contra esa opinión logró imponerse una ajustada mayoría del Politburó, a la que pertenecían Jruhchov y Bulganin, que abogaron por una postura más moderada y sugirieron que permitir una liberalización «relativa» en Polonia y Hungría, con elementos partidarios del comunismo nacional, sería suficiente para poner fin ai peligro. Para justificar su posición dieron como razones la crisis económica creciente de la URSS, que no estaba en condiciones de emprender otra guerra, las tensiones interiores del régimen y el poder en ascenso de China, que no iba a consentir tan fácilmente un avance soviético hacia Europa ${ }^{15}$.

La postura moderada fue la que triunfó, como es sabido, y, según el informante, asi se impuso a Gomulka en Polonia, tras la adecuada "puesta en escena" "16 y a Nagy en Hungría, después de que la URSS destituyera a Rákosi en julio de 1956 y nombrara nuevo Secretario General del Parti-

15 Esa idea del "avance ruso hacia Europa" no está corroborada por ninguna otra fuente y encaja sospechosamente con la visión que dieron los EE.UU. durante las décadas de 1950 y 1960 respecto a las intenciones del "avance soviético hacia Occidente". Ya habian aludido a ello durante la guerra de Corea, cuando dieron a Europa la versión de que la participación de los comunistas en ese enfrentamiento no era más que un ensayo para avanzar posteriormente hacia Europa.

16 El Informe afirma que la aceptación por la URSS de Gomulka, en octubre de 1956, tras la destitución de Ochab cuando las protestas de los obreros de Poznan de 1955, fue una estrategia del círculo de Jruhchov para calmar los ánimos permitiendo tomar el mando a un partidario de las "vías nacionales al socialismo" - al igual que ocurrió cuando Jruhchov se reconcilio con TitoFara congraciarse con Polonia frente a la dificil situación de división dentro del Kremlin. AMAEX, R-4294-6. Esto era algo obvio que va se comprobó cuando Jruhschov fue a Polonia y tuvo que esperar a "ser recibido" por Gomulka, con lo que éste le hizo una demostración simbólica de sus apoyos en el pais. 
do Comunista húngaro a Erno Gerö. Esa destitución de Rákosi es interpretada por la Embajada de España en Viena como resultado de las antipatias que había cosechado tanto por parte de Tito - al que tanto había criticado cuando su secesión de la URSS en 1948 - como por parte de Jruhchov - que no había tenido inconveniente en calificarle de estalinista-, pero también porque Gerö, el sucesor, era el «verdadero ojo de Moscú" desde que Rákosi había iniciado su decadencia ${ }^{17}$. En Hungría había surgido en ese momento la insurrección nacional, en principio, por un incidente inesperado: al parecer, una patrulla rusa no había sido informada de que la manifestación del 23 de octubre había sido autorizada y abrió fuego sobre la masa, lo que hizo saltar la reacción general.

En cuanto al carácter del levantamiento, se señala, una vez más, que fue secundado por la práctica totalidad de la nación, y se sostiene que, aunque estuviera liderado por jóvenes hasta los 25 años, "estuvieron apoyados por todo el mundo". El Informe indica incluso que la ausencia de una preparación o programación de los hechos supuso el éxito de la empresa porque el Gobierno de Gerö se encontró entre la espada y la pared: quedó atrapado entre una lucha sin precedentes en las calles y una huelga general, masivamente seguida.

\subsection{La composición de las tropas soviéticas}

La actuación de las tropas soviéticas en el enfrentamiento con la insurrección fue un aspecto de primordial importancia. Como también lo fue el intenso rechazo que manifestó cada sector de oposición, siendo «la retirada de las tropas soviéticas de Hungría" uno de los puntos que no faltó en ningún listado de reivindicaciones. No obstante, es necesario distinguir entre las tropas que estaban apostadas en Hungría desde 1948 y las que llegaron en esos días y protagonizaron la invasión del 4 de noviembre de 1956.

Las tropas apostadas en Hungria eran tropas del ejército soviético que llevaban tanto tiempo que habian entablado todo tipo de relaciones con la población húngara, y entre ellas se dieron las deserciones más importantes que se unieron a los insurrectos. El caso más emblemático fue el de Pal Maleter, que después sería Ministro de Defensa con Nagy y que estuvo al frente de esas tropas destacadas en Hungría. De ese modo, el régimen comunista de Gerö no tuvo más apoyo que el de la temida policia política

\footnotetext{
Despacho de la Embajada de España en Viena del 21 de julio de 1956. AMAEX, R-4465-88.
} 
-la AVH_, compuesta por unos 10.000 hombres, la mayoría no húngaros, que estuvieron dispuestos a cargar sin consideración alguna.

Las tropas soviéticas que protagonizaron la invasión de Hungría llegaron en 1956 y fueron sistemáticamente rechazadas por la población húngara. Tan claros e insistentes se mostraron los deseos del pueblo a este respecto que Kádár se vio obligado a dar repetidas seguridades en diversas declaraciones del mes de noviembre de 1956 y en meses posteriores acerca de que la retirada de las tropas soviéticas sería uno de sus principales objetivos. Ya el 18 de noviembre de 1956, el diario comunista de Kádár - Népszabadsag - que era el portavoz oficial del gobierno, sostuvo que la independencia de Hungría exigía que no hubiera tropas extranjeras estacionadas en suelo húngaro. Después, sin embargo, se fue abandonando el tema y la explicación que daban siempre respecto a la permanencia en suelo húngaro era siempre la misma: que las tropas se mantenían en virtud del Tratado de Varsovia, lo que era una falaz justificación. Según los artículos 4 y 8 del Pacto de Varsovia sólo era legal la intervención de la organización en caso de agresión externa y ello debía ser compatible con la no injerencia en los asuntos internos de otro país.

Esos principios se vieron corroborados al año siguiente por la declaración soviética del 30 de octubre de 1956 que, en referencia al xx Congreso del PCUS, reafirmaba que trataría de "remediar las violaciones y errores que hubieran tendido a perturbar el principio de igualdad en las relaciones entre los países socialistas". Según esa declaración, la URSS, a partir de ese momento, aseguró que aplicaría el principio leninista de la igualdad de las naciones en sus relaciones con otros países socialistas y su cumplimiento por la URSS habría constituido el primer elemento en la normalización de la situación, tal como se había planteado en la Asamblea General, aunque no se había cumplido. Por ello, cuando en la ONU se adoptó la medida solemne de pedir la retirada de las fuerzas soviéticas, era lógico suponer que la URSS se atendría a lo acordado. Como es obvio, tampoco en esta ocasión fue así y el mandato de la ONU no se cumplió. Más recientemente la permanencia de las tropas en Hungría se había actualizado por el acuerdo celebrado el 27 de mayo de 1957 entre el Gobierno Kádár y la URSS. ${ }^{18}$.

La procedencia de las tropas estacionadas en Hungria es otro punto importante para explicar su comportamiento. Sólo las que se encontraban ya en Budapest desde el primer momento, al estallar la lucha, eran proce-

18 Informe de la Comisión Investigadora de los hechos de Hungria, en el XV Período de Sesiones de la Asamblea General de la ONU, 1 de diciembre de 1960. AMAEX, R-7465-7. 
dentes de la Rusia europea y estuvieron de principio a fin "sumidas en un profundo desmoronamiento moral» al comprobar el apoyo que el ejército húngaro había prestado en Hungría a los insurgentes. Más tarde, cuando ya existió una voluntad firme de aplastar el pais, fueron traídas otras 5 divisiones soviéticas, que se sumaron a las anteriores y que ni sabian dónde se encontraban ni cuál era su cometido. A este respecto del origen asiático y de la desorientación, coincide por completo este Informe con la exposición de los hechos de Gabriel Ronay, en la memoria de su marcha hacia la frontera para salir de Hungria. Dice así:

"Nos encontramos con muchos soldados que entraban en la capital. La confusión era verdaderamente alarmante: unos que iban en un tanque grande y que llevaban detrás un convoy de vehículos armados, y a $1 \mathrm{Km}$. de Budapest, les dijeron que iban a Berlín para aplastar un levantamiento fascista. Otros, que encontraron más tarde a unas 70 millas al Oeste, eran tropas de Asia Central rusa y les dijeron que habían llegado a ayudar a sus hermanos musulmanes atacados por los imperialistas y les pidieron que les enseñaran el Canal. Los que estábamos allí no tuvimos la menor duda de que sus comisarios políticos, que habian estado preparando "tropas voluntarias" para una posible intervención soviética en Suez, no habian tenido tiempo de cambiar de disco en el adoctrinamiento y no les había supuesto ningún problema. Llevamos a Kirghises y Khazakstanos a un arroyo cercano, que no era el Canal de Suez, y no pudieron ver ningún imperialista británico ni ningún hermano musulmán por ningún lado" ${ }^{19}$.

Esas 5 divisiones eran "tropas venidas de unidades de la antigua PoIonia Oriental y de la Ucrania Carpática», lo que es indicativo, por una parte, de los lugares de acuartelamiento en zonas de la Rusia europea, más cerca de la frontera rusa con Europa, y, por otra, de que en el nada homogéneo ejército soviético había algunas divisiones formadas integramente por elementos asiáticos, en concreto por Kirghises y Khazakstanos en esta ocasión.

\subsection{Las motivaciones que dieron lugar a la decisión de invadir Hungría}

La decisión de invadir en el preciso momento en que se hizo suscitó una atención especial entre los contemporáneos porque fue un hecho totalmente inesperado. Las tropas habían estado acuarteladas hasta el día 1 de noviembre, pero ese día se dio la orden de que se retiraran del país en su totalidad. Esa orden estuvo en vigor hasta la tarde del día 1, de modo

19 RONAY, Gabriel: “The Indian Connection", en New Hungarian Quartely, vol. 33, 1992. 
que empezaron a retirarse y las 5 divisiones asiáticas, que penetraron en Hungría por Rumania y por la Ucrania Carpática en la noche de ese mismo día 1 , se cruzaron en la frontera con las que se retiraban del país. Desde el día 2 la entrada masiva e ininterrumpida de tropas fue ya innegable. Según Aguirre -en total coincidencia con otras muchas fuentesese cambio brusco de actitud de la URSS, esa decisión de invadir fue consecuencia de los sucesos de Próximo Oriente, de la invasión de Israel a Egipto. La decisión de entrar en Hungría, dicen los Informes, había sido tomada después de recibir "importantísimas informaciones» que, tanto en las cancillerías de la Europa Continental como entre personas de la mayor influencia y autoridad de Austria, Suiza y Francia, se consideraron del todo fiables puesto que se basaban en despachos autorizados recibidos de Londres. Teniendo presente que ya había comenzado el conflicto de Suez y se tenía noticia de la probable intervención de Francia e Inglaterra, en dichos Informes, al parecer, se hacian sugerencias por parte de Sir Anthony Eden sobre la conveniencia de los soviets de abstenerse de intervenir en la zona del Canai para que pudieran tener una presencia más activa en Hungría ${ }^{20}$.

Esas "sugerencias̈» se interpretaron por la URSS como un aviso de que les convenía a cada potencia concentrarse en su respectiva zona de influencia y pudieron tener un peso importante en la actitud del Kremlin de confiar en que Occidente no se inmiscuiría en un área que no fuera la de su ámbito estricto. Cuando más adelante el ataque franco-británico a Suez fue un fracaso y le costó el prestigio al gobierno del ministro británico $A$. Eden, él sostuvo insistentemente que había sido una coincidencia la decisión de las fechas en los ataques de Hungría y Suez. Las opiniones de George Mikes ${ }^{2:}$-que Eden se autoengañaba - y de Charles Gati, estudioso de las Memorias de Jruhchov, coinciden con las interpretaciones del Informe que se recibió en España respecto al peso que tuvieron en Rusia las "sugerencias británicas", en el sentido en que se esperaba que el ataque a Suez distrajera la atención del mundo" ${ }^{22}$.

Otra información simultánea en noviembre de 1956 manifestaba los temores que aún tenían los diferentes observadores occidentales respecto a que la URSS pudiera emprender otras acciones. Así, salió a colación de nuevo la reunión secreta de septiembre del Politburó en la URSS y los

20 Informes enviados por el Embajador de España en Bonn, Antonio María Aguirre, al Minis. terio de Exteriores español. AMAEX, R-4294-6.

27 Mikes, G.: “Eden, Nagy y Kádar» en Contemporary Review, n. 250, 1987, págs. 16 a 20.

22 Gat!, Ch.: “Imre Nagy and Moscow, 1953-1956". Problems of Comımunism, n. 35/3, 1986. págs. 32 a 49 
apoyos que había tenido la propuesta de lanzarse a una guerra en Europa. Todo ello se relacionaba en los primeros días de noviembre con el hecho de que "se había producido una concentración de fuerzas y carros blindados en la antigua Prusia Oriental, Polonia Oriental y Checoslovaquia, así como con que 13 de las 22 divisiones que tenian los soviets en ese momento en la República Democrática Alemana, se dirigían hacia la frontera polaca". Ahora, según esa Memoria, parecía que se apoyaba la tesis de que la URSS podía estar pensando en atacar Polonia.

En nuestra opinión, y a la vista del desarrollo posterior de los acontecimientos, más que ningún intento de invasión de Polonia —que había frenado sus posiciones en cuanto conoció la respuesta rusa en Hungríalas tropas podian estar en la frontera polaca a la espera de acontecimientos inesperados 0 , incluso, preparadas ya para el regreso puesto que el ataque brutal del 4 de noviembre les había proporcionado una victoria rápida en Hungría. No existen datos adicionales para dar crédito a ningún otro intento de ataque soviético contra ningún otro país de la Europa del Este ${ }^{23}$.

\subsection{Las demandas de ayuda a España}

En España lo primero que se hizo fue atender a las múltiples peticiones de ayuda humanitaria y de acogida de refugiados, que surgieron de forma inmediata desde todas las organizaciones. Los informes españoles de noviembre de 1956 sobre este particular son de autocomplacencia tanto en lo que se refiere a la respuesta monetaria, como a la simpatía y solidaridad mostradas por los españoles hacia la causa húngara. En España se consideró que la ayuda humanitaria se necesitaba en dos ámbitos diferentes: para los expatriados en el extranjero y para la población que no pudo salir en la misma Hungría. Habían llegado, como a otras partes, noticias de que la necesidad de ayuda para los expatriados - sobre todo refugiados en Austria - era muy apremiante, pero también se sabía que, según cálculos de la Cruz Roja Internacional, se necesitarian en la propia Hungria $150.000 \mathrm{Tm}$. de harina y otros víveres para que sobrevivieran los que allí habian permanecido hasta la próxima cosecha. Era asimismo urgente el envío de ropas de abrigo porque en Budapest, por causa de los disparos de los tanques, la mayoría de las casas estaban sin cristales y sin carbón para calefacción. Aguirre concreta que España ya había envia-

23 Memoria sobre los hechos de Hungria del 14 de noviembre de 1956. AMAEX, R-4466-2. 
do, inmediatamente después de los hechos, dos aviones, siete camiones y tres trenes de arroz y algo más tarde realizó envíos masivos de ropas y otros enseres.

Por lo que respecta a los refugiados, la opinión que prevaleció fue la de ayudar a Austria a mantenerlos allí, cerca de su patria, pues los que eran trasladados a Ultramar era muy difícil que regresaran y se consideraban perdidos para Hungría. Los que pudieran llegar a España debían recibir una «ayuda realista» que tuviese en cuenta que sería para varios años y no se podía dilapidar dándoles de una vez y a su llegada todo lo que les correspondiera ${ }^{24}$.

Desde la Embajada de España en Viena, se envió una carta de agradecimiento por las ayudas logradas para Hungría, por la que conocemos que los medicamentos, ropas y alimentos que se acumularon fueron distribuidos por la Cruz Roja, Cáritas, el delegado general del servicio de ayuda húngara, Laszlo Taubinger, el delegado especial del Señor Arzobispo para esos efectos, M. Ungar, y el Príncipe Batthyany. También se mencionó en esta ocasión a los 35.000 refugiados que habian huido a Austria y por causa de los cuales se habian hecho llamamientos a todos los países para contribuir con el Gobierno austríaco a su manutención y cuidado. La necesidad parecía extrema y con el Informe se daban detalles de que la necesidad era tan acuciante que en los comedores instalados en Viena al efecto, había habido días en que no se había podido ofrecer más que pan y queso. Igualmente se supo que muchos niños habian cruzado la frontera sólo con un cartelito al cuello, encomendándoles a la caridad austríaca. Ante esa realidad, se decidió que no salieran de Austria los niños sin ir acompañados por sus madres, para que los que estaban solos pudieran, más adelante, contactar más fácilmente desde Austria con los familiares que les quedaran en Hungría. Pero esa determinación de que los niños permanecieran o salieran siempre con sus madres también encarecía los traslados y la manutención en Viena, por lo que era urgente la ayuda que se solicitaba preferentemente monetaria ${ }^{25}$. También se aceptaron en España peticiones individuales de asilo, siempre que estuvieran avaladas por alguien solvente, como varios casos que preseritó Marossy y de los que aclaraba que su "situación financiera era de toda garantía» ${ }^{26}$.

24 Memoria... AMAEX, R-4466-2

25 Despacho Consulado General de España en Viana, del 19 de noviembre de 1956. AMAEX, R-5.628-21.

26 Es el caso de Georgy Yacoby, en España desde 1930, que solicita por medio de Marossy y directamente, visados para tres sobrinos que podrian seguir sus estudios en España. De él, en efecto, subraya Marossy que tiene unas posibilidades económicas fuera de dudas y que es miem- 
No fueron éstas, sin embargo, las únicas peticiones de socorro que recibió España. De nuevo por mediación de Marossy se solicitó otro tipo de ayuda, mucho más comprometedora y arriesgada "y que sólo España puede proporcionar: el apoyo de aquellas fuerzas activas que luchan por la liberación» ${ }^{27}$. Por ese motivo se manifestaba que sería deseable que la ayuda española se dividiera en dos: una parte, para las obras de caridad y beneficencia; pero otra, que debía ser sustancial, para futuras necesidades de la lucha anticomunista, de las que no cabía esperar ayuda en otros países ${ }^{28}$. Esas palabras son muy significativas de la claridad con la que, en la Oficiosa Legación Real húngara de España, se conocía la fuerza del estatus quo de la Guerra Fría, que les llevó a no concebir esperanzas de colaboración que no fuera estrictamente humanitaria por parte de ningún país del mundo, según ellos, con la excepción de España. Vuelve a confirmarse la imagen que se tenía de España, ante todo y por encima de todo, de anticomunista, por lo que un supuesto delegado húngaro, Alejandro Bako, se había atrevido a hacerle la propuesta de lanzar observadores en paracaídas. Si bien es cierto que esa demanda inicialmente no tuvo eco, sí se intentó después encontrar una región donde pudieran ser arrojadas armas anti-tanque, también en paracaídas. La pérdida de la región de Szombathely y la situación crítica del sur de Dunafoldvar, que eran las dos zonas donde se habian estado haciendo preparativos y se había intentado en esos días restablecer un contacto, hizo imposible la misión finalmente "dada la pasividad de los medios militares occidentales» ${ }^{29}$.

Otras medidas que se sugirió emprender al Gobierno español fueron las orientadas a realizar esfuerzos para que la Comisión de Investigación de la ONU pudiera entrar en Budapest, como se habia acordado desde la resolución emitida el 4 de noviembre - y que no aceptaron finalmente en el interior de Hungría-, y para la vigilancia en las elecciones que aún se creía que deberian celebrarse. Esto último no deja de sorprender cuando España no tenía precisamente un régimen legitimado por unas elecciones. Pese a ello se valoró, también en esta ocasión, su posición

bro conocido de la colonia húngara en España. La expresión que utiliza Yacobi en su solicitud es que sus sobrinos están en Viena porque han podido "escapar del terror rojo". Carta de Giorgy Yacobi Kirchner, del 4 de diciembre de 1956, al Ministerio de Asuntos Exteriores. AMAEX, R-5628-22.

27 Comunicado secreto de la Legación Real de España en Hungría. Noviembre, 1956. AMAEX, R-4466-2.

${ }^{28}$ Incluyen en dicha ayuda la subvención a "patriotas", en caso de reanudarse la sublevación, acciones clandestinas de socorro, gastos de acciones de propaganda, políticas, e, incluso, en último caso, militares.

29 Es frecuente en los comentarios de los diplomáticos españoles la expresión de este tipo de lamentaciones de que no se actuara más decididamente en varias ocasiones en Hungría por causa de la tibieza occidental. 
anticomunista y esa consideración hizo que Franco viviera la insurrección húngara, como señala L. Suárez Fernández, como «la aparición de un anticomunismo militante que devolvía al régimen español, primer vencedor de una revolución soviética, el prestigio que se le había negado hasta entonces» ${ }^{30}$.

En resumen, de los diferentes canales españoles de información diplomática, se deduce que todos consideraban que la situación europea se había transformado de la noche a la mañana y que se encontraba en un punto crítico en el que la pasividad de Occidente no había servido más que para inyectar nueva vida al régimen soviético ${ }^{31}$. A la vista de todo lo anterior, se puede creer razonablemente que, si España hubiera encontrado eco en otros países para ofrecer ese otro tipo de ayuda, de envío de armas 0 , incluso, de hombres para luchar, lo hubiera hecho, pero no la encontró. A este respecto, L. Suárez Fernández sustenta la tesis de que el fundamental obstáculo para que la empresa de intervención directa española se llevara a cabo fue que el día 6 de noviembre se consideró ya aplastada toda la resistencia. En efecto, como ya señalamos con referencia al informe del embajador Aguirre, la zona de Szombathely, que se había pensado para la entrada de los paracaidistas, había caído el día 5 y ese hecho cerró las posibilidades ${ }^{32}$. Otras versiones ponen el acento sobre todo en que España lo hubiera intentado, pero EEUU se negó en rotundo a emprender ningún tipo de acciones militares ${ }^{33}$.

\section{EL INFORME DEL EMBAJADOR DE ESPAÑA EN VIENA, JOSÉ SEBASTIÁN DE ERICE}

De parte del Embajador de España en Viena, José Sebastián de Erice llegó a España otra versión muy personal de los hechos plagada de adjetivos y calificativos de gran utilidad para comprender la visión de nuestro embajador en Viena del contexto del levantamiento húngaro. Erice sostenía en su informe algunas interpretaciones de los hechos, de las que él no tenía duda, pero que, en algunos de los casos, no son corroboradas por el resto de las fuentes. Los temas que trata aluden a las posiciones de

30 Suarez Fernandez, L.: Franco y la URSS. La diplomacia secreta (1946-1970). Ed. Rialp, Maoirid, 1987.

Informe sin firma adjunto a despachos del Embajador Antonio María Aguirre, del 5 de noviembre de 1956. AMAEX, R-4294-6.

32 Suarez Fernandez, !., ob. cit.

33 Entrevista citada con Zoltan Ronay. 
los diferentes actores del conflicto, como la actitud de Tito, la pasividad de EEUU y el endurecimiento de las posiciones de la URSS y su brutalidad, mencionando cifras de fusilamientos insólitas. Por último habló sobre los fundamentos de la revolución sin que parezca por sus palabras que hubiera captado lo que se había pretendido con la insurrección húngara. Para él todos los comunistas eran iguales y no establece matices.

\subsection{La actitud de Tito}

Es uno de los temas a los que dedica más atención y sostiene que Tito había estado detrás del levantamiento húngaro, pero se volvió en su contra cuando Nagy "se le fue de las manos". Dado que, según Erice, fue distinto el levantamiento en la capital y en el resto del país -en Budapest y las grandes capitales fue «rojo cien por cien», en palabras literales de Erice, mientras que en las provincias tomó un carácter anticomunista- Tito creyó conveniente que hubiera un gobierno mixto y llevó a cabo gestiones para que se negociara en Hungría un "Frente Patrićtico", con Nagy a la cabeza, pero en el que hubiera socialistas y agrarios, como Zoltan Tildy y Bela Kovacs. Tito había sido incluso el primero que había enviado «medicamentos" ${ }^{34}$ a los componentes del círculo Pettofi cuando se alzaron contra Gerö, pero cuando vio que sus "juguetes», Nagy y Pal Maleter, habian sido desbordados, aconsejó que se utilizaran tropas soviéticas. De hecho, cuando Tito protestó en la ONU fue por la represión de las tropas y por la actuación de Kádár, pero no por el hecho en sí de la intervención soviética. No obstante, después, cuando Tito vio la forma de proceder de las tropas rusas, según Erice, sí quiso que salieran de Hungría pero también porque deseaba que Hungria quedara en deuda con Yugoslavia.

Más tarde, sin embargo, supo por el Embajador de Yugoslavia en Viena, Uvalich que, según Erice, era su fuente de información, que Tito había escrito a Bulganin recriminándole sobre la intervención rusa en Hungría porque perjudicaba a todos e informándole de que la opinión pública del mundo entero y los partidos de la Segunda Internacional en primer lugar, habían tomado partido por los "combatientes de la libertad" - freiheitkampfern - ya que el problema de Hungría requería una solución política y no militar y que había sido un error ocupar con las tropas soviéticas todo el país. En su opinión hubiera bastado para la seguridad de la URSS con las guarniciones. Opinaba que el Gobierno Kádar no

34 El entrecomillado es de Erice, en el original. AMAEX, R-4465-89. 
podía restablecer el orden en Budapest y le advertía que Yugoslavia no podía quedar al margen, por lo que solicitaba ser consultado sobre los pasos que iban a darse en el futuro ${ }^{35}$.

No se mencionan aquí algunas de las razones que más fundamento parecen tener y que han sido esgrimidas por Pierre Maurer, respecto a los temores de Tito: que si no se hubieran retirado de Hungria las tropas rusas habrian podido penetrar en Yugoslavia por la llanura de la Vojvodina serbia y Tito hubiera tenido que enfrentarse realmente con la URSS; o que, si finalmente triunfaba el pluripartidismo en Hungría, podian regresar al país "elementos de Horthy", irredentistas de antaño, que quizá hubieran cuestionado las fronteras de Yugoslavia por el Norte, en zonas limítrofes con Hungría ${ }^{36}$.

Tito, en cualquier caso, aparece ante Erice como alguien contradictorio: casi había arrancado literalmente de las manos soviéticas a Nagy y a sus ministros cuando les ofreció asilo en su Embajada y permitió hasta finales de noviembre que pasaran por su frontera provisiones para los guerrilleros, sin embargo, había pronunciado en Pola un discurso a mediados de noviembre claramente filosoviético. En cualquier caso, la opinión de Erice queda resumida en un texto que reproducimos por su interés:

"Tito ha manipulado el tema húngaro y el fondo de la cuestión no es más que se está trasladando la central de Moscú a Be!grado, lo que es mucho más perjudicial para Occidente. Yo prefiero tener al comunismo confinado en las estepas rusas, al fondo del Kremlin, y rodeado de satélites que Occidente pueda ir erosionando, a tenerlo en las márgenes del Adriático desde donde irradiaría hacia el Oeste antes o después. A Tito le ha interesado mucho la Hungria neutral que propone Nagy: después de la brutalidad soviética, en Hungria, los "coexistentes" ya no pueden decir que son "amigos de la democracia" y "amigos de la URSS", pero si "amigos de la democracia" y "amigos de Yugoslavia". La situación es tan propicia para hacerse un hueco importante entre los "coexistentes" que es imposible que no lo advierta la 'formidable y tremebunda megalomanía de! dictador yugoslavo" ${ }^{37}$.

35 Como se comprobaría más adelante, aún con esa imagen que daba Tito de que se le tenia en cuenta, estuvo claro que a la URSS le importó muy escasamente su criterio, ni en el tema de la agresión, que continuó en Hungria, ni en el destino de los líderes húngaros asilados un tiempo en la Embajada Yugoslava.

36 MAURER, P.: "Tito et la revolution hongroise: autopsie d'une méprise polítique", Schweizarische fur Geschichte, n. 43/1, 1993, págs. 142 a 148.

${ }^{37}$ Informe del Embajador español en Viena, José de S. Erice. AMAEX, R-4465-89. Es destacable que Erice haga el mismo anáisis de la personalidad de Tito que P. Maurer (1986), al atribuirle como caracteristica tan sobresaliente su megalomania. 


\subsection{La pasividad de EEUU}

En opinión de Erice, hubo una «indiferencia brutal» por parte de EEUU por coincidir la insurrección con las elecciones americanas, lo que tuvo como consecuencia "una caída vertical de su prestigio en Europa Occidental». En Austria, por ejemplo, se creyó que después del día 6 de noviembre, en que ya Eisenhower habia ganado las elecciones, se iban a enviar viveres $y$ medicamentos a Budapest por medio de la división norteamericana Constabulator, que estaba concentrada en la frontera cercana a Munich. Incluso se pensó que la actitud rusa de no ocupar la frontera austrohúngara habia sido debida a que la URSS no tuvo dudas de que Norteamérica intervendría y, si eso hubiera ocurrido, la URSS hubiera podido acusar a Nagy de que, pese a proclamarse neutral, había pedido ayuda a EEUU. Pero como la ayuda norteamericana no liegó, los países fronterizos con los comunistas también se inhibieron y ello se tradujo en un incremento de las "posiciones neutralistas» ante el ejemplo dado por Austria y en una desvalorización del comportamiento de Occidente en el área. Aún así, la casi totalidad de su prensa austríaca se manifestó a favor de los combatientes húngaros y fue del todo favorable a la actitud de acogida de refugiados.

Erice critica la actitud de EEUU y la falta de sentido político de algunos representantes que cometían errores como el sufrido por Taubinger $-\mathrm{y}$ que él le relató muy confidencialmente a nuestro Embajador- que no habia sido recibido por ninguno de los Secretarios de la Embajada norteamericana, sino por la taquígrafa del Embajador y al que esa actitud le habia dolido mucho. O la lentitud y escasez de la ayuda humanitaria para socorro de los refugiados en estos primeros dos meses, de una desproporción tan grande con su capacidad económica.

\subsection{El endurecimiento de las posiciones de la URSS}

La última de las cuestiones tratadas por Erice, y de la que culpa en parte a la indiferencia ante el tema húngaro de EEUU, fue el permitir que la URSS se radicalizara en sus posiciones. Y para él fue prueba irrefutable de ello el nombramiento de Molotov como Ministro de Control, que era un puesto tan importante como el de Secretario General del Partido o Presidente del Consejo, o sea, como los puestos de Jruhchov o Bulganin ${ }^{38}$. Como ya señala-

38 Como argumentos que corroboren lo que se afirma aqui, Erice señala que Molotov "odia a España" y que tiene gran amistad con Konief, al que, por su desprecio a la sangre, "hasta los rojos llaman 'rojo". AMAEX, R-4465-89. 
mos, la URSS pensó que EEUU intervendría y a finales de noviembre todavía lo creía, lo que para Erice queda demostrado por el interés que los rusos tuvieron en volar puentes fronterizos y por la calidad del armamento tan modernísimo de que se habian dotado que no hubiera tenido sentido para combatir a guerrilleros descalzos y con escopetas de caza, o "casi de chispa", como él dice textualmente. No se sabía de dónde había sacado la URSS ese armamento desconocido hasta por los Agregados Militares Occidentales que «ni los mejores servicios secretos consiguen romper el telón de misterio a lo largo del Danubio y que incluyen cinco modelos nuevos de tanques, un lanzallamas de gas y un fusil ametrallador de 36 disparos" ${ }^{39}$.

Erice se lamenta de que, como el pueblo húngaro estaba llevando a cabo una resistencia heroica y Rusia quería una salida digna a cualquier precio, había vuelto a hablar con EEUU sobre reducción de armamentos - aceptando la inspección aérea cara al General Eisenhower ${ }^{40}$ - y le había propuesto la creación de una zona neutral en Europa, que incluiría Hungría, de la que se retirarían los ejércitos de ambas potencias. Dado que EEUU parecia dispuesto a negociar sobre ello, Francia e Inglaterra y el nuevo Secretario General de la OTAN Spaak - del que dice Erice que es "socialista y, por ende, "pacifista" - recogieron esas ideas de "zona franca» pero con otra interpretación: el crear algo que enfatizara la cooperación europea y no fuera exclusivamente militar: un "mercado común» el «Euratom», que hiciera hincapié en nuevos aspectos de la OTAN y modificara totalmente su esencia, concebida inicialmente como instrumento defensivo de la agresión militar comunista. Erice lo consideraba un error y argumentaba que EEUU, por estar sufriendo una crisis de carburantes desde el ataque a Suez, parecía muy proclive tanto a pactar con la URSS, como a convertir a la OTAN en un elemento de cocperación económica y él temía que ese acuerdo con la URSS diera «al traste con las ventajas que supondría el resquebrajamiento de ese conglomerado comunista para los principios españoles» ${ }^{41}$. Se aprecia de una forma clara que a Erice no le agradaba en absoluto que se avanzara en la "coexistencia pacífica",

39 No existen noticias posteriores que despejen ese "misterio", en palabras de Erice. La incredulidad era debida a la resistencia de loS EEUU a creer que la URSS pudiera estar más adelantada que ellos en armamento, pero no hay otra explicación en esos momentos para la sorpresa que rnanifiesta.

40 Es una afirmación extraña ésta de que la URSS aceptaría la inspección aérea del General Eisenhower. Hay que recordar que, sólo cuatro años después, en 1960, pasada la segunda crisis de Berlin, cuando se iba a celebrar la Cumbre de París entíe EEUU. Francia, Gran Bretaña y la URSS, Jrushchov se enteró de que EEUU había enviado vuelos de reconocimeintos U2, vuelos espias, y por ello se negó a participar en la Cumbre y poco después optaria por elevar el muro de Berlín

${ }^{41}$ Informe sobre Hungría de Erice del 21 de noviembre de 1956. AMAEX, R-4465-89. 
sino que prefiere que Occidente mantenga una oposición frontal ante el comunismo.

También relata alarmado que en Hungria se estaba fusilando por millares y se disimulaba en un buen número de casos llevando a los prisioneros a las barreras fronterizas para matarlos allí y que pareciera que se les habia disparado al intentar huir; denuncia que se estaban produciendo deportaciones en masa a Siberia, incluso de niños de 10 años y parecía que hubieran planeado terminar con el movimiento por hambre, pues el Gobierno Kádár restableció los cupones de racionamiento, pero sólo se entregaban a la salida de las fábricas y como las huelgas no cesaban, la mayoría de la población no conseguía cupones. También hace referencia a que se sucedian los juicios sumarísimos por toda Hungría y a que en diciembre de 1956 habian salido unos 145.000 huidos a Austria. Erice se permite incluir en su informe un deseo personal y dice que ha pedido a Dios «ayuda para la rápida eliminación de los Nagy y comparsa, de actuación tan dudosa como nefasta" pues los culpa de la victoria soviética por no haber sido verdaderos jefes:

"Al traidor Nagy, que ha propiciado contubernios con los Agrarios y ha preferido vender su patria antes que ver triunfar un movimiento nacionalista y hasta el célebre Pal Maleter, al que llaman 'el héroe de Budapest' y que hemos sabido que perteneció a las tristemente famosas 'brigadas internacionales'. Sólo los más decididos han pasado a la guerra de guerrillas y a los núcleos móviles de la resistencia" ${ }^{42}$.

Finalmente, señala que, cuando el día 4 de noviembre entró el dispositivo militar soviético en Hungría, se dio «la mayor tragedia y vergüenza de la historia moderna de la civilización" y a finales de mes aún no habían llegado los observadores de la ONU que, si todavía llegaban, ya no verían nada de los que antes habrían debido observar. La realidad, sin embargo, como conocemos, superó los temores de Erice y a los observadores no se les permitió entrar a Hungría nunca. Sus últimas palabras, antes de firmar su informe, merecen, una vez más, ser reproducidas:

"Hay que temer, o quizá que esperar, que algún día Occidente sienta la conciencia de su deber, del deber que hoy han sentido las masas populares, ese deber que sólo España y nuestro Caudillo han clamado ante el mundo,

42 Erice llama traidor a Nagy porque dio la órden de alto el fuego, por lo que los revolucionarios, según él, se abandonaron en la creencia de haber obtenido la victoria y suspendieron una marcha que habian proyectado sobre Budapest para el dia 1 de noviembre. Entonces los soviets se concentraron en puntos vitales y después ocuparon todo el pais. Tampoco consideró válido a Maleter en cuanto se enteró de que pertenció a las brigadas internacionales. 
ese deber que España y nuestro Caudillo han recordado con insistencia porque es imperativo de orden moral, ese deber fallido en los 'grandes' y en su virtud - nunca mejor tal vocablo: por virtualidad y por ascendencia - un nuevo incidente en los Balcanes produzca que se aplique a la URSS el castigo que su torvo proceder en Hungria, ha merecido ya» ${ }^{43}$.

Casi un año después, en septiembre de 1957, la Asamblea General de la ONU emitió una nueva resolución condenando firmemente lo ocurrido en Hungría, en base al Informe del Comité Investigador del junio anterior. En esa ocasión, fue el Embajador español en la ONU, señor Lequerica, el que envió un extensa Exposición de hechos a España explicando la inclusión de nuestro país entre el grupo impulsor y, al hilo de esa explicación, enumeró una serie de consideraciones que permiten una ampliación cualitativa de riuestro conocimiento sobre la percepción española de lo ocurrido en Hungría.

\section{EL INFORME DEL DELEGADO DE ESPAÑA EN LA ONU, JOSÉ FÉLIX DE LEQUERICA}

Lequerica lamenta que las sesiones de la ONU tengan que dedicarse a recriminarse unos países a otros, pero dado "lo atroz de lo ocurrido en Hungría y lo palmario de la intervención soviética", considera que no hay otro camino. Los asuntos que trata en su exposición son: la presencia de España en la ONU y sus opiniones coincidentes con el representante de EEUU, Cabot Lodge, y el de Portugal, Belaúnde. Que España no aceptara en ningún momento las excusas dadas por la URSS para justificar la intervención en Hungría del Pacto de Varsovia y expresa su apreciación personal acerca del personaje de Nagy. Por último, niega que la revolución húngara fuera un levantamiento fascista.

\subsection{La presencia de España en la ONU}

El hecho de que el Gobierno español fuera el primero en dirigirse al Secretariado de las Naciones Uridas, cuando apenas habian llegado noticias de protesta contra lo que estaba ocurriendo en Hungría, fue un motivo de orgullo para los políticos españoles y así lo manifiesta Lequerica. Él lo califica de un hecho excepcional, pero dice que fue posible porque,

${ }_{43}$ Informe del Embajador español en Vieria, José de S. Erice. AMAEX, R-4465-89. 
en su opinión, España no necesitaba el Informe de la Comisión Investigadora de las Naciones Unidas, que se conoció más tarde, para saber una buena parte de lo que eran los procedimientos soviéticos, ya que habia habido un ensayo en España entre 1936 y 1939. Condena enérgicamente la entrada violenta de Rusia en Hungría y busca de inmediato la analogía con las tropas soviéticas que habían invadido Hungría para ayudar al Gobierno húngaro de Gerö, en contra de la insurrección, con las brigadas rojas que habían entrado en España para ayudar a los republicanos españoles, apoderándose de sus organizaciones oficiales y expulsando al Gobierno existente.

Con motivo de la presentación del Informe de la Comisión de Investigación, Lequerica destaca la actitud de Nagy, y, por su actitud en las sesiones, la de Cabot Lodge o Belaúnde. Por lo que se refiere a Nagy, Lequerica dice de él:

"...Todos sabéis que merece nuestro respeto por los sufrimientos que le han acarreado sus antecedentes políticos, pero también que era un comunista muy fiel a Moscú. Nagy empezó a ser, en contra de lo que él mismo esperaba, símbolo de la unidad del pueblo húngaro. En los días siguientes al 24 de octubre pareció vacilar entre la lealtad de su formación marxista, respaldada por un aparato de fuerza y la adhesión a la causa de sus compatriotas. En rigor fue un personaje - no caben bromas en materia tan gravemuy dentro de la tradición de los teatros español y francés: nosotros tenemos "El médico a palos" y Francia tiene la maravilla de "Le medecin malgré lui", un hombre colocado en una situación que no soñaba, pero que al final -y esto refleja la realidad del tremendo movimiento húngaro- se sintió húngaro, rompió sus vínculos puramente oficiales con un gobierno extranjero y, mejor o peor, sirvió a su país» ${ }^{44}$.

Aún así, hace saber su propia posición en la Asamblea, cuando, ante el escrito condenatorio por las ejecuciones de Nagy y su grupo, él se opone hasta donde le es posible a que se aluda a ellos como "patriotas", pese a que son comunistas. Asimismo, se refiere en forma elogiosa al representante americano, Cabot Lodge, y se manifiesta de acuerdo con él en su apreciación de que Hungria, en rigor, no se había sentido libre desde 1946, aunque se guardaban las formas y no se había llegado a una situación de violencia. Por ello, en cuanto fue posible, estalló en un movimiento revolucionario. En el mismo sentido, ensalzó también el discurso de Be-

44 Comentario de Lequerica acerca del Informe de la Comisión de Investigación sobre los hechos de Hungría de las Naciones Unidas. AMAEX, R-5.046-53. 
laúnde, resaltando un parte de su discurso de apreciaciones similares a las de Cabot Lodge:

"Cuando murió Stalin, se produjo "un 1848" para el mundo soviético, como el que en aquella fecha desencadenó una evolución doctrinal en toda Europa y cambió el orden existente. Por ello, los húngaros, que no habían aceptado más que por la fuerza, en esos 9 años, una situación de sumisión a la URSS, en cuanto creyeron que el propio país dominador indirecto evolucionaba y abría sus caminos a una posible mayor libertad, se lanzaron candorosamente, pero con una grandeza de entusiasmo y fervor, de la que ellos mismos habían dado ya ejemplo en la Historia, a conseguir el camino de su libertad» ${ }^{45}$.

Por lo que se refiere a la posición española sobre la intervención que había tenido la URSS en Hungría, a las "legalidades" en qué se amparó y a si se podia excusar su proceder por la pertenencia de ambos países al Pacto de Varsovia, Lequerica la define claramente como una intervención de la URSS en un país soberano. Además, la acusa de contravenir lo establecido en la Carta de Naciones Unidas: "Los miembros de la Organización, en sus relaciones internacionales, se abstendrán de recurrir a la amenaza o al uso de la fuerza contra la integridad territorial o la independencia política de cualquier Estado o en cualquier otra forma incompatible con los Propósitos de Naciones Unidas» ${ }^{46}$. El Pacto de Varsovia en ningún caso autorizaba a Rusia a entrar en Hungría ni en ninguno de los países asociados, si no había ninguna amenaza de agresión armada y en Hungría no había habido amenaza exterior alguna. Las únicas amenazas, desde el día 24 de octubre, en opinión de Lequerica, eran las dirigidas a la URSS en las emisiones de radio americanas, la organización Cáritas y los prelados y nobles, o personas de título, que regresaban a su país.

También con relación a las reacciones que provocó el Informe de Investigación que se presentó en la ONU, se aprecia con claridad la idea española de lo que se podía hacer para ayudar y, aunque había habido ciertas tentaciones de haber intervenido militarmente o de haber enviado ayudas de armas y otras manifestaciones dice Lequerica:

"Yo he oído críticas a la debilidad de los acuerdos de la Asamblea General, pero, aunque con la Carta en la mano se hubiera podido incluso liegar a la guerra, dudo mucho de que alguien deseara de verdad una guerra y la-

45 Belaunde era el Representante de Portugal en las Naciones Unidas. Discurso de la sesión en que se presentó el Informe de la Comisión de Investigación sobre los hechos de Hungría de las Naciones Unidas. A/PV.637. AMAEX, R-5.046-53

46 Párrafo 4 del artículo 2 del articulado de Naciones Unidas. 
mento las críticas de la prensa que repiten constantemente que se abren nuevos periodos de sesiones en la Asamblea General, pero que todo queda en palabras. Yo creo que esas palabras son muy necesarias y una gran prueba de consideración y el emplear un lenguaje suave en el Informe, como habia resaltado el representante del Reino Unido, no quiere decir, en modo alguno, que la indignación de la ONU estuviera agotada" ${ }^{47}$.

\subsection{El levantamiento no fue un estallido fascista}

Por lo que se refiere al argumento empleado por la URSS con frecuencia respecto al peligro que existió en el levantamiento de emergencia del fascismo, aunque Lequerica atribuye a la URSS «poca autoridad moral para escudarse en que las libertades estuvieran amenazadas", admite la hipótesis de que la URSS dudara acerca de las competencias que les otorgaba el Tratado de Paz de 1947 y apunta que lo que hubiera sido demostrativo de interés por la legalidad hubiera sido apelar al articulado en que ese punto se aclara del Tratado de Paz: "Toda diferencia relativa a la interpretación de la ejecución del Tratado que no se hubiera resuelto por la vía de las negociaciones diplomáticas directas, será sometido a los tres jefes de misión en Budapest: Reino Unido, URSS y EEUU ${ }^{48}$, Es decir, que lo prudente hubiera sido, si temian un peligro de resurgimiento fascista, que la URSS se hubiera entrevistado con los embajadores de EEUU e Inglaterra en Budapest y hubieran deliberado los tres acerca del asunto, pero eso no se hizo. Al respecto de si hubo o no influencias externas, fascistas o de otro tipo, expondremos nuevamente las palabras literales de Lequerica por la rotundidad con que atribuye un carácter de levantamiento espontáneo a los sucesos de Hungria:

“¡Ni había amenaza ni habia fascistas de ningún género!. Lo que hubo fue un levantamiento tremendo, cuya naturaleza no conviene tampoco confundir porque no es posible pasar revista a cada uno de los sublevados. Claramente se ha visto que pertenecian a todas las ideologías y que en ellos abundaban elementos comunistas y elementos obreros. Porque como lo definió el Ministro de Asuntos Exteriores de Irlanda, el Sr. Aiken, era un movimiento nacional, que trascendia barreras de clase y de partido y que se negaba a calcular lo que le podía costar ${ }^{49}$.

Para teminar, otro punto importantísimo que queda claro en su exposición, y que es un error muy extendido en la secuencia de los hechos de

47 Comentario de Lequerica (...)AMAEX, R-5.046-53.

48 Artículo 40 del Tratado de Paz de 1947. Documento A/PV.637. AMAEX, R-5.046-53.

49 Comentario de Lequerica (...)AMAEX, R-5.046-53. 
Hungría de 1956, es que no hubo petición del Gobierno húngaro de Nagy de ayuda a Rusia, como tantas veces sostuvo la URSS a modo de justificación para su entrada. El Gobierno húngaro, desde la madrugada del día 24 de octubre de 1956, había estado presidido por Imre Nagy y a quien Nagy pidió ayuda de forma desesperada fue a las Naciones Unidas, ante la sorprendente invasión de las tropas rusas, lo que también es de sobra conocido y que no niega ninguna fuente que se precie de ser fiable. Fue Gerö el que había tratado con la URSS, le había expuesto la situación alarmado y había solicitado refuerzos, pero eso no constituía una petición oficial del Gobierno legítimo de Hungría y, a ese respecto, el Embajador español no tiene ninguna duda ${ }^{50}$.

Como puede comprobarse en estos Informes, las cuestiones relativas a Europa del Este se trataban en España más de lo que por lo general se ha conocido. Ocuparon bastante el tiempo de nuestros políticos y España tuvo en ellas un interés, hasta primordial a veces, en su afán por mantenerse en un puesto de primera fila en la cruzada contra el comunismo.

\section{FUENTES Y BIBLIOGRAFIA}

\section{Bibliografía}

ARendT, Hanna: On revolution, New York, Viking Press, 1963.

CASTORIADIS: "The hungarian source", en Telos, 1976.

DEUTECHER, Isaac: "La tragedia del partido comunista polaco", en El marxismo de nuestro tiempo. El Era, México, 1975

Donnbach, A.: The Secret Trial of Imre Nagy. Praeger Publishers, 88 Post Road West, Westport, CT06881. United States of América, 1994.

ESTARRIOL, R.: "Los testigos mudos de Occidente: Hungría 1945-1948, el camino al socialismo", en Analyse, Viena, 1965, recogido por el mismo autor en "La Europa Comunista, 1945-1990m.

FehER, F. y Heller, A.: Hungary 1950, Revisited: The message of a revolution a quarter of a century after. London, Allen and Unwin, 1982, traducido como Análisis de la revolución húngara. Ed. Hacer, Barcelona, 1983.

Gat।, Charles: "Imre Nagy and Moscow, 1953-1956", Problems of communism, vol. $35, \mathrm{n} .{ }^{\circ} 3$ Duke University Press, 1986.

GonzÁlez EnRIOUEz, :C.: Crisis y cambio en Europa del Este. La transición húngara a la demo cracia. Ed. Centro de Investigaciones Sociológicas. S. XXI Editores. Madrid, 1993.

GutiérRez Álvarez, José: “1956: reforma en Polonia, revolución en Hungria», en Historia $y$ vida, vol. 19, n. $225,1986$.

Hellema, Duco: «Relevance and irrelevance of dutch anti-communism: the Netherlands and the hungarian revolution, 1956-1957", en Journal of Contemporary History, vol. 30, 1995.

HiRmondo, A.: The Messenger, n. ${ }^{\circ}$ 2, diciembre de 1983.

KRASSO, Gyorgy: Instituto "Imre Nagy" en Bruselas -Szemle (Revista)—, vol. 5, n. 3,1963 y en otro libro titulado The Truth about the Imre Nagy affair, en Secker and Warburg, London, 1959. 
Lomax, Bill: Hungary, 1956, Londres, 1976. (Allison and Busby, London, 1976), en la "Samizdat» húngara titulada Magyarorszag, 1956 (Budapest, 1979, reeditada por el "Magyar szabadsaghereos vilaszovetseg"-Asociación Mundial de combatientes por la libertad de Hungria-, Calgary, Canadá, y en París por «Magyar Fuzetek» and Dialogues Européens»).

MIKES, Goerge: "Eden, Nagy y Kádar" en Contemporary Review, n. ${ }^{\circ}$ 250, 1987.

MOLNAR, Miklós y NAGY, László: ¿Imre Nagy, ¿réformateur ou revolutionaire?. Ginebra, Libraire E. Droz, París Libraire Minard. MOLNAR, M.: Budapest, 1956. A history if de Hungarian revolution. Londres, 1971 ,

NaGY, Imre: On communism: In defense of the new course. New York, 1957, (Memoranda que Nagy difundió en Hungría entre 1955 y 1956).

RaINER, János M.: "Reprisals". Mew Hungarian Quartely, vol. 33, n. 127, pags. 118-127, 1992.

RonaY, Gabriel: "The Indian Connection», en New Hungarian Quartely, vol. 33, 1992.

SALDANAA, José.: "Budapest 1956: victoria en la derrota". Historia y vida, vol. 16, 1983.

SuÁrez Fernandez, L.: "Hungría, el Consejo de Seguridad y el oro de Moscú", en Franco y la URSS: Ia diplomacia secreta (1946-1970). Madrid, Ed. Rialp, 1987.

TAIBO, C.: «El deshielo Krustchoviano», en La Unión Soviética (1917-1990), Ed. Síntesis, Madrid, 1993.

VALI, F.: Rift and revolt in Hungary: Nationalism versus Communism. Cambrigde, Londres, 1961

2. Documentos del Archivo del Ministerio de Asuntos Exteriores (AMAEX) y del Ministerio de la Presidencia del Gobierno, Jefatura del Estado

- Carta del Cónsul de España en Munich, R. F. Quintanilla, del 20 de octubre de 1956, AMAEX), R-4466-2.

- Carta de Marossy del 26 de octubre de 1956. AMAEX, R-4294-6.

- Telegrama n. 86 del Delegado de la ONU. Archivo del Ministerio de la Presidencia del Gobierno. Jefatura del Estado, Leg. 1686, 1.1

- Telegrama n. 87 del Delegado de la ONU. Archivo del Ministerio de la Presidencia del Gobierno. Jefatura del Estado, Leg. 1686, 1.1.

- Telegrama n. 89 del Delegado de la ONU. Archivo del Ministerio de la Presidencia del Gobierno. Jefatura del Estado, Leg. 1686, 1.1.

- Telegrama n. 90 del Delegado de la ONU. Archivo del Ministerio de la Presidencia del Gobierno. Jefatura del Estado, Leg. 1686, 1.1.

- Carta del Embajador de España en Bonn, Antonio M.. Aguirre, del 7 de noviembre de 1956. AMAEX, R-4465-89

- Informes de los días 7, 14 y 20 de noviembre de 1956 del Embajador de España en Bonn, Antonio M. Aguirre. AMAEX, R-4465-89.

- Informes de los días 21 al 27 de noviembre de 1956 del Embajador de España en Bonn, Antonio M. ${ }^{\underline{a}}$ Aguirre. AMAEX, R-4465-89.

- Informe de AMAEX, R-4294-6.

- Despacho de la Embajada de España en Viena del 21 de julio de 1956. AMAEX, R-4465-88.

- Informe de la Comisión Investigadora de los hechos de Hungria, en el XV Periodo de Sesiones de la Asamblea General de la ONU, 1 de diciembre de 1960. AMAEX, R-7465-7.

- Informes enviados por el Embajador de España en Bonn, Antonio María Aguirre, al Ministerio de Exteriores español. AMAEX, R-4294-6.

- Memoria sobre los hechos de Hungría del 14 de noviembre de 1956. AMAEX, R-4466-2.

- Despacho Consulado General de España en Viena, del 19 de noviembre de 1956. AMAEX, R-5.628-21.

- Carta de Giorgy Yacobi Kirchner, del 4 de diciembre de 1956, al Ministerio de Asuntos Exteriores. AMAEX, R-5628-22.

- Comunicado secreto de la Legación Real de España en Hungría. Noviembre, 1956. AMAEX, R-4466-2.

- Informes sin firma adjuntos a despachos del Embajador Antonio Maria Aguirre, del 5 de noviembre de 1956. AMAEX, R-4294-6. 
- Informe sobre Hungria del Embajador José de Erice del 21 de noviembre de 1956. AMAEX, R-4465-89.

- Comentario de Lequerica acerca del Informe de la Comisión de Investigación sobre los hechos de Hungria de las Naciones Unidas. AMAEX, R-5.046-53.

- Intorme de la Comisión de Investigación sobre los hechos de Hungria de las Naciones Unidas. A/PV.637. AMAEX, R-5.046-53

- Tratado de Paz de 1947. Documento A/PV.637. AMAEX, R-5.046-53 